\title{
VIDEO REVIEW
}

\author{
Carnivals of the Caribbean: Puerto Rico/Trin- \\ idad/Martinique. 2004. By Sonia Fritz, director, \\ and Frances Lausell, producer. $60 \mathrm{~min}$. DVD \\ format, color. (Isla Films, San Juan, Puerto \\ Rico.)
}

\section{JoHn H. McDowell \\ Indiana University}

This vibrant production has something of the flair and energy of its subject matter, as it switches from one island to another in an effort to document the making of carnival in these settings and to confront some of the issues that swirl around carnival performances. The basic method here is to inject short snippets of carnival actions into a more leisurely fabric of interviews with both scholars and participants, with special attention paid to the men and women who conceive of and execute the schemes presented in carnival costumes, floats, and parades. The pace of the film is rapid and the movement from one setting to another swift, but this documentary scores well as a teaching resource on the basis of the excellent quality of its footage, both interview material and scenes of carnival in action.

Carnivals of the Caribbean is organized around a set of themes addressed in the carnivals of the three selected islands: Puerto Rico, Trinidad, and Martinique. First, the scene is set and viewers are given a brief visual tour of the sites we will be visiting in the video. These scenes are useful because they allow us to perceive the radical changes carnival works upon the streets, districts, and cities where it takes place. The video then takes us behind the scene to view preparations going into the making of carnival: costume, mask, and float design, and the arrangement of musical productions and dance steps. We then experience the realization of carnival in its parades and varied performances. In closing, we view the demise of carnival in the burning of effigies and the farewell until the new year brings carnival's return. As we progress through this inventory of themes, we meet and hear from the people who make these things happen and from those who are inclined and entitled to comment, with well-chosen footage spliced in to illustrate each topic.

A good deal of the commentary seeks to get at the meaning of carnival-its "magic" and "mystique," as the female narrative voice frames it. In the words of scholars and practitioners, carnival is presented as a release from the normal restrictions of life-as one speaker has it, "the liberation of oppressed vitality." One sees carnival mischief as "testing the waters"; another tells us that "one mocks everything" during carnival. Several speakers point to symbolic displays of sensuality and sexuality as the crux of the matter. But other, more redemptive themes are at play as well-reconciliation, renewal, the expression of diversity, and even religious devotion, when, for example, promesas are fulfilled with ribbons tied to Santiago's statue in Puerto Rico. To the credit of those who created this documentary, many voices are heard and no simple solutions are provided. As a consequence, carnival retains its vitality and even gains some in the viewing of this video.

Several controversies are adumbrated if not fully explored in Carnivals of the Caribbean. In Trinidad, some people are using masks drawn from Halloween in preference to the traditional masks; in Puerto Rico, carnival themes are deeply influenced by American television. These episodes point to an underlying concern with authenticity and purity, clearly difficult concepts to sustain in the all-consuming flames of island carnival. But the eternal struggle goes on, and curators of tradition do constant battle with the innovators on the street, scoring occasional triumphs but steadily yielding ground to the wandering folk imagination. Issues of authenticity are tied to issues of carnival consumption, with questions of image and tourism implicated in the debate. Carnival obviously has the potential to attract tourists, as it does, especially in the case of Trinidad's world-famous celebrations. The positive image of a people at play, the glamour and glitter of carnival costumes, the thrill of carnival music — all these form a foundation for lucrative tourism during carnival time. But 
the other side of this image- the excesses, the libertinism, the hedonism, the sense of a world out of control-has the potential to keep many tourists away (though admittedly, to draw some as well). Issues like these are discussed extensively in the scholarly literature, and they receive a vivid if cursory glance in Carnivals of the $\mathrm{Ca}$ ribbean.

The strength of this video lies in the way it opens a vista into the making of carnival by featuring the words of those who make it happen and those who reflect on this process. The snippets of carnival action are enticing but rarely extend beyond five to ten seconds, which means that we are never drawn into the hypnotic spell of carnival as its percussive and vibrant elements accumulate. Moreover, the continuous shifting from one scene to another and from one voice to another prevents us from engaging deeply with any single scene or person. There is a trade-off here: the makers of this video have opted for a rapid-fire, highly energized visual and acoustic texture, and in turn they have abandoned any hope of immersion in a specific carnival episode, personality, or theme. As a consequence, this video lends itself to some purposes and not to others. It works as an enticing introduction to carnival on three Caribbean islands, with a wonderful soundtrack, excellent interviews, and suggestive glimpses of actual carnival scenes. Beyond this surface, it raises in preliminary form a set of issues worthy of extended debate, relating to the meaning of carnival, the struggle between tradition and innovation, and the role of carnival in island tourism. This video is particularly valuable for taking us behind the scenes to meet those who create the costumes, floats, and music that fuel carnival celebration. I can see making selective use of footage in this video in undergraduate classes to illustrate essential features of carnival and of Caribbean culture. 